\title{
Nesting Record of the Lark Sparrow
}

By Doug Gilroy, R.R. No. 1, Regina

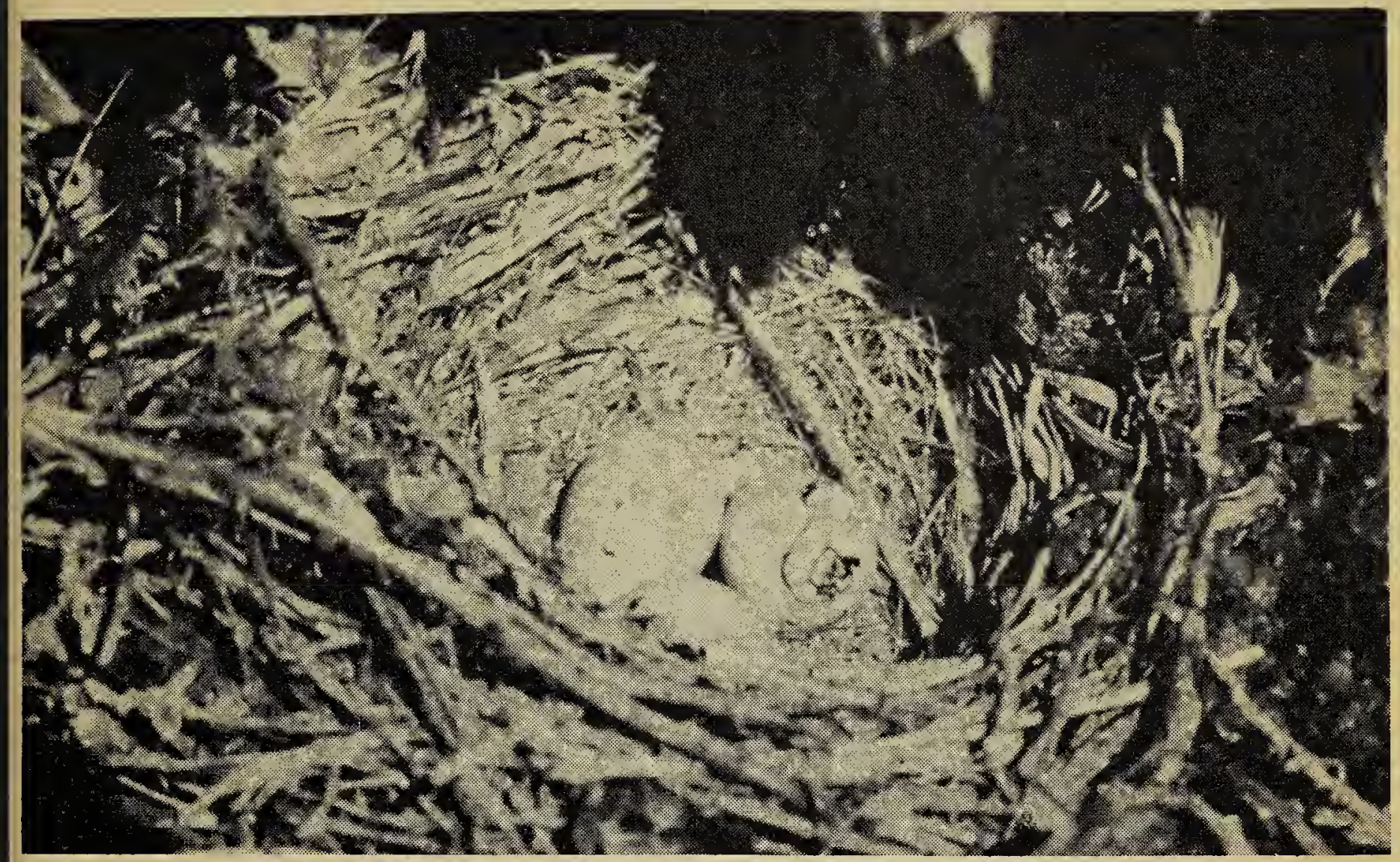

Nest and eggs of the Lark Sparrow photographed July 30, 1958, on the Gilroy farm near Brora, Sask. The nest was built on the ground at the base of a fine, large specimen of the Nodding Thistle (Carduus nutans L.).

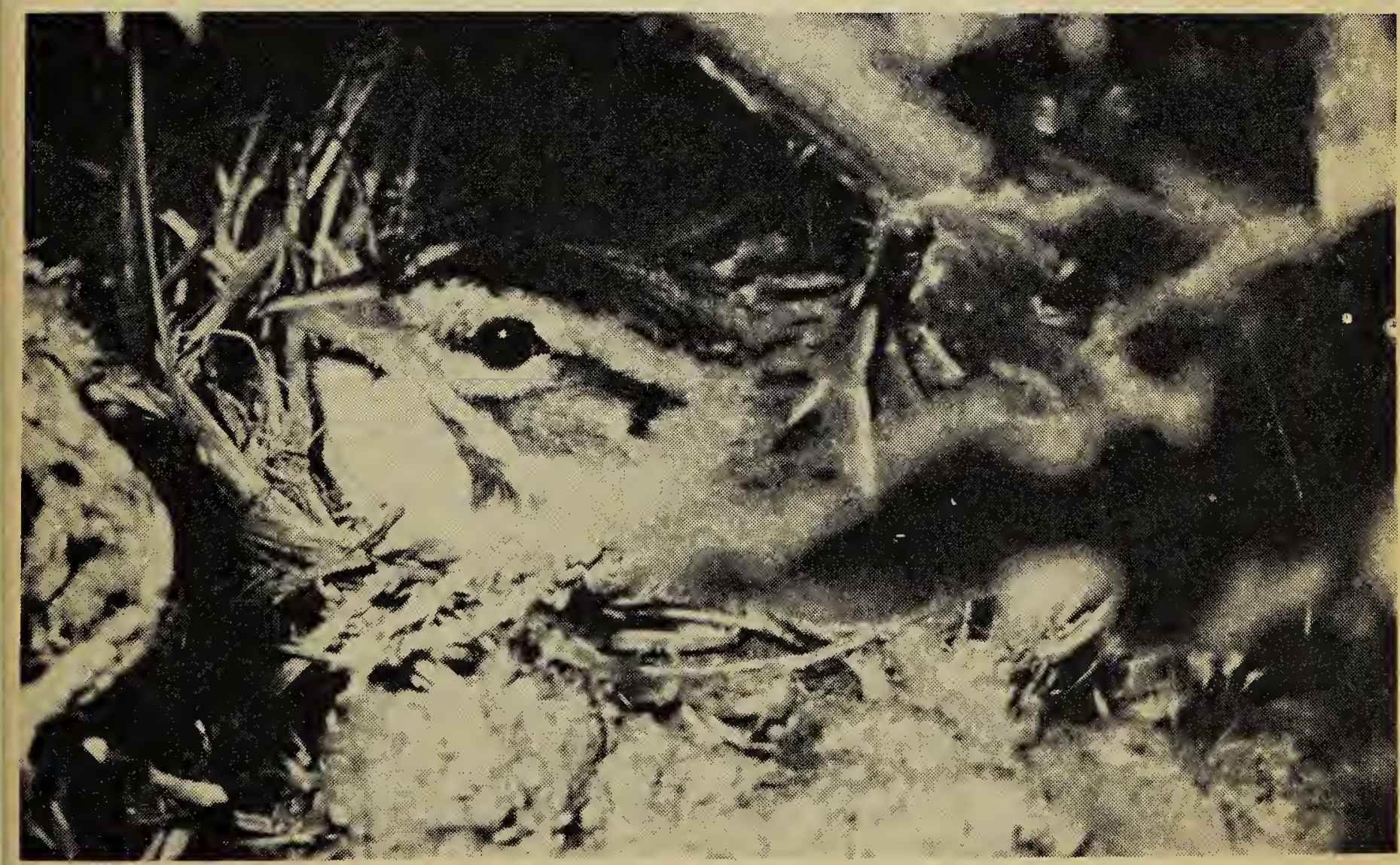

Lark Sparrow on the nest, July 30, 1958. Lark Sparrows have been observed in this area for several years, but this is the first nest located. 